

\title{
THE ROLE OF STATE IN VARIETIES OF CAPITALISM (SVOC), ACHIEVEMENTS AND CHALLENGES FOR CENTRAL AND EASTERN EUROPE AND THE EMERGING MARKETS (A CONFERENCE REVIEW)
}

\author{
MiCHELLE CROSBY-NAGY ${ }^{1-Z S U Z S A N N A ~ G E ́ R I N G ~}{ }^{2}$
}

On the 26-27th of November, the Central European University's Center for EU Enlargement Studies and the Hungarian MTA KRTK VGI co-hosted several presentations and keynote lectures at the CEU campus in Budapest. The conference proved highly attractive for our community of economic sociologists in light of the recent response to the framework provided by CEU's Dorothee Bohle, as well as the presence of high profile scholars in the field; namely, Martin Myant and Andreas Nölke.

Sessions were organized into the following themes: EU and VoC; Banking sector and SME financing; CEE and VoC; Nationalization, Privatization and Household Debt; Emerging Markets; Welfare policies; Crony Capitalism; and Labor policies. Opening speeches by Balázs Péter and Szanyi Miklós revealed the challenges, but also the potential for VoC to facilitate communication across disciplines. Differences in discourses across disciplines became clear even from these opening talks about what is meant by the "roles of the state" and at what level: national vs. supranational intervention and/or the interaction of the two. Szanyi Miklós, remarked that there are many things at the national perspective that are inspiring for him at the micro level, and a need to try to reconcile and connect these two perspectives.

Martin Myant gave a particularly insightful address titled: What framework should we use for analyzing varieties of capitalism in East-Central Europe? He raised significant questions with regard to the theoretical underpinnings of $\mathrm{VoC}$ with his analysis of the Czech case. In his introduction he argued,

\footnotetext{
1 Michelle Crosby-Nagy is Ph.D. student at CUB (michelle.crosby@uni-corvinus.hu) and senior staff development assistant at the UN High Commissioner for Refugees. The views expressed herein are those of the author and do not necessarily reflect the views of the United Nations/UNHCR.

2 Zsuzsanna Géring is research fellow, Budapest Business School; gering.zsuzsannamargit@gkz.bgf.hu
} 
"VoC is potentially bad economics, sociology and political science". Problems include: its static classifications, lack of accounting for dynamisms and forces of stability, its firm centrality, lack of accounting for the role of groups, as well as the extremism of the two ideal types: liberal market economies and coordinated market economies. Myant argued to go back to the theory's implicit Marxian roots-one that would account for changes as well as causality (infrastructure explaining superstructure, or not).

This re-examination is important, he contested, because a Marxian approach is right and wrong at the same time. It is right in the sense that its central point is the economic system, and it focuses on the internal logic of the economic system, which has impact on social structure and on politics (and these react back upon system). Of course, Marxian theory was wrong due to its premise about the end of capitalism. The capitalist economic system was not collapsed by its internal economic logic, but by the political act of revolution (labor against capitalists); therefore, we should elaborate a model where different forces play crucial roles in continuous change. Myant declared, these interrelated forces include economics, social change and politics and their varieties and similarities can serve as the foundations of different capitalistic models.

He proceeded with a rigorous historical break-down of the Czech case into time periods: 89-92; 93-98; 99-2006; and 2006-present, insisting that such a grouping has to be adapted to each country, and may not fit for all. In a Polányian fashion (though it was not self-identified as such), he directly confronted 'dependent market economy' (DME) theory by assessing national level protectionist policies such as women's paid leave and the manner in which they developed; concluding that the multinational organization was actually not the center of everything, at least in the Czech case. There can be dependency, but this does not drive everything, he stated.

Despite Myant's encouragement of the incorporation of social change, his presentation was confronted by several unanswered questions about how we can reconcile the changes that occurred during these periods with the desires and beliefs of the populous. For example, it was posed, what can we make of the idea of "double dependency", which argues that there are two forms of dependency, one on the state in the form of expectations of protection from market reforms, and one on multinationals in the form of market-based opportunities. A similar question was raised, "If you go outside of this room, most people will tell you they are not capitalists and this is not capitalism-so how can we incorporate this into VoC?"

The keynote speaker of the second day was Andreas Nölke, the high impact author of the 'dependent market economy' model in which $\mathrm{VoC}$ is applied to $\mathrm{CEE}$ countries. In his presentation 'State-permeated capitalism in large 
emerging markets', Andreas Nölke did not address our region, but rather the large emerging economies. The title illustrates the main topic of Nölke's recent research, which tries to answer the question: how can we explain the rise of these countries from a comparative capitalism perspective?

Andreas Nölke and his group believe they have developed a novel VoCmodel, "state-permeated capitalism" based on special features of large emerging countries. They elaborated the characteristics of this new model along with the main dimensions applied to the other three types of the VoC-model (liberal, coordinated and dependent market economies). As Andreas explained in his lecture, this model is an ideal-type (like the other three); therefore not all countries fit perfectly at every point, but the main features are present in every one of them. The model is built on the framework of the $\mathrm{VoC}$-school, i.e. the identification of the main coordination mechanisms and the specification of the five institutional spheres of the analyzed markets.

Based on this approach, in the case of 'state-permeated capitalism', the main coordinator is the state, but the role of the state is not directing a centralized, top-down steering mechanism (as in Japan), but rather building cooperation between various state and business coalitions. These partnerships are based on loyalty and trust, on shared social (elite) background and on informal relations. As for the five institutional spheres, the national market plays the defining role for corporate governance and the most important sources of financing in investment are internal savings at local banks. Strong segmentation of the labor force is typical of industrial relations, but not as the sector-protection division in coordinated market economies, but between very high-level and very low-level segments.

High division is characteristic in education and training as well; namely, a large part of education covers general skills while a very small portion of the system supplies extremely high-level training. Last but not at least, innovation is "technology lending"; where, reverse engineering and R\&D is financed largely by the state. Supplementing these coordination mechanisms and institutional features with the specialization of large emerging economies is the advantage of their large domestic markets. This is a market model where the size of the domestic market can guarantee a good negotiation position in international relations and some degree of stability despite globalised processes (such as economic crisis). However, the strong concentration of power within the state and national capital has its limits for democracy and it leads to a high level of corruption and extreme inequality.

After the introduction of this new model, Nölke supported his key points using data from the analyzed markets, and pointed out the similarities and the differences among them. The presentation generated a lively debate with thought- 
provoking questions from the audience, which revealed not only the interest of the listeners, but their expertise as well.

Overall, the conference generated fresh momentum for the concentration of VoC researchers here in CEE and offered an inspiring exchange of ideas about the applications of VoC-theory. We look forward to detailed information with regard to any future directions of the potentially new research program. 